\title{
WORKSHOP PELATIHAN PERANCANGAN INTERNET OF THINGS BERBASIS ARDUINO UNO JENIS R3/R3 SMD DI SMK SWASTA KARYA UTAMA KOTA TANJUNGBALAI
}

\author{
Ricki Ananda ${ }^{1}$, Muhammad Amin ${ }^{1}$ \\ ${ }^{1}$ Sistem Komputer, STMIK Royal Kisaran \\ email: ${ }^{1}$ rickianandainterface@gmail.com
}

\begin{abstract}
Current technological developments are no stranger among students, almost all students now have an Android that is enabled to share information and be used to help with daily activities. Based on the usefulness of android which is only enabled to share information or as a communication tool, the service team creates training or workshops which later aims to develop students' interest in reviewing or developing technology in the field of android or in the controller field. In order for the training not to start from the ground up, the training participants were taken from the main works of private vocational schools, majoring in computers, class XI of the Department of Software Engineering (RPL), with a total number of participants of 53 people. The implementation of a two-day workshop found results, on the first day with the theme of training on IOT-based automatic switch hardware design, it was found that 46 students managed to assemble automatic hardware switches, and 7 students failed to assemble the hardware automatically perfectly. On the second day, 53 students succeeded in making an automatic software switch on Android, and during the trial, all students also managed to do it. From the two days of the workshop activities, and seen from the students' activeness and curiosity about the development of Android and the controller, many students still want to know, other developments from Android besides being used as automatic switches are based on IoT.
\end{abstract}

Keyword: Royer Oscillator circuit, Power wireless transfer, Booster converter circuit

\begin{abstract}
Abstrak: Perkembangan teknologi saat ini sudah tidak asing dikalangan pelajar, hampir semua pelajar kini memiliki android yang difungsikan untuk berbagi informasi serta difungsikan untuk membantu kegiatan sehari hari. Berdasarkan kegunaan android yang hanya difungsikan untuk berbagi informasi atau sebagai alat komunikasi, maka tim pengabdian membuat pelatihan atau workshop yang nantinya bertujuan untuk menumbuh kembangkan minat siswa siswi dalam mengulas atau mengembangkan teknologi dibidang android dibidang controller. Agar pelatihan tidak dimulai dari dasar, maka peserta pelatihan diambil dari SMK Swasta karya utama, jurusan komputer, kelas XI Jurusan Rekayasa Perangkat Lunak (RPL), dengan total peserta 53 orang. Terselenggaranya workshop selama dua hari,mendapati hasil, pada hari pertama dengan tema pelatihan perancangan hardware switch otomatis berbasis iot, didapati 46 siswa berhasil merangkai hardwarei switch otomatis, dan 7 siswa tidak berhasil merangkai hardware otomatis secara sempurna. Dihari kedua, 53 siswa berhasil membuat software switch otomatis di android, dan pada saat uji coba, seluruh siswa juga berhasil melakukannya. Dari dua hari kegiatan workshop yang dilakukan, dan dilihat dari keaktifan dan rasa ingin tahu siswa tentang pengembangan dari android dan controller, banyak siswa yang masih ingin tahu, pengembangan lain dari android selain digunakan sebagai switch otomatis berbasis iot.
\end{abstract}

Kata Kunci: Royer Oscillator circuit, Power wireless transfer, Booster converter circuit 
Available online at https://jurnal.stmikroyal.ac.id/index.php/jurdimas

\section{PENDAHULUAN}

Jaringan nirkabel atau umum disebut jaringan Internet of Things, atau dikenal juga dengan singkatan' IoT, merupakan sebuah konsep yang bertujuan untuk memperluas manfaat dari konektivitas internet yang tersambung secara terus-menerus. Adapun kemampuan seperti berbagi data, remote control, dan sebagainya, termasuk juga pada benda di dunia nyata. Contohnya bahan pangan, elektronik, koleksi, peralatan apa saja, termasuk benda hidup yang semuanya tersambung ke jaringan lokal dan global melalui sensor yang tertanam dan selalu aktif. Workshop Pelatihan Perancangan Internet Of Things Berbasis Arduino Uno Jenis R3/R3 Smd akan dilaksanakan Di Smk Karya Utama Kota Tanjungbalai.

Tujuan dilakukan nya workshop pelatihan IOT di SMK Swasta Karya Utama, agar siswa/i jurusan Rekayasa Perangkat Lunak (RPL) bisa menggabungkan antara perangkat lunak (Software) yang selama ini dipelajari, dengan perangkat keras (Hardware) berupa controller dari Arduino Uno R3/Jenis SMD R3yang akan diajarkan oleh tim pengabdian.

Pelatihan ini diharapkan nantinya jadi bekal mereka untuk bersaing dalam memperoleh pekerjaan ataupun bekal mereka untuk melanjutkan pendidikan dibidang komputer di tingkat perguruan tinggi. Di massa saat ini, penguasaan software juga harus didampingi dengan penguasaan hardware, terutama dibidang controller dan IoT.

Dari pemarapan diatas, diharapkan para siswa/i mampu mengembangkan dan menggabungkan kedua perangkat tersebut dalam sistem Internet of Things, sehingga pelatihan ini, perlu dilakukan di SMK Swasta Karya Utama kota Tanjungbalai.

\section{METODE}

Pengabdian yang dilakukan di SMK Swasta karya utama kota tanjungbalai, menggunakan metode dan model pembelajaran jenis alat peraga dan model pembelajaran praktek. Siswa yang dijadikan peserta dalam pelatihan IOT, merupakan siswa kelas XI RPL 1, dan 2. Dengan jumlah 25 orang untuk siswa RPL 1, dan 28 orang untuk siswa RPL2.

\section{PEMBAHASAN}

\section{Pengenalan hardware controller Arduino Nano}

Arduino merupakan papan elektronoik (electronic board) yang berisi mikrokontroller produksi atmel, tepatnya mikrokontroller atmega 328. Atmega 328 memiliki 3 buah port utama, yaitu portB, portC, dan portD. dengan totap pin i/o sebanyak 23 pin, sumber tegangan $5 \mathrm{v}$ dan flash memori $32 \mathrm{~kb}$ [1]. Arduino yang digunakan jenis arduino jenis nano, dengan jumlah pin digital 13 bit, dan jumlah pin analog 6 bit. dan tegangan $3,3 \mathrm{~V}$ dan 5 VDC. Dengan tegangan 5-12 VDC, dan tegangan kerja 5 VDC.

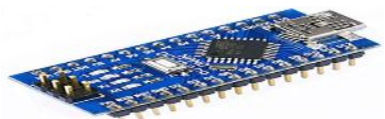

Gambar 1. Board Arduino Jenis Nano

\begin{tabular}{lllr} 
Relay & & & \\
Relay adalah & Saklar & (Switch) yang \\
dioperasikan & secara listrik dan \\
merupakan & \multicolumn{2}{c}{ komponen Electro } \\
mechanical & (Elektro mekanik) yang
\end{tabular}


Available online at https://jurnal.stmikroyal.ac.id/index.php/jurdimas

terdiri dari 2 bagian utama yakni Elektromagnet (Coil) dan Mekanikal (seperangkat Kontak Saklar/Switch). Relay menggunakan Prinsip Elektromagnetik untuk menggerakkan Kontak Saklar sehingga dengan arus listrik yang kecil (low power) dapat menghantarkan listrik yang bertegangan lebih tinggi [2]. Jenis relay yang digunakan dalam penelitian ini menggunakan modul relay 3 chanel, dengan tegangan kerja relay 110-220 VAC. dan tegangan kedua 5VDC.

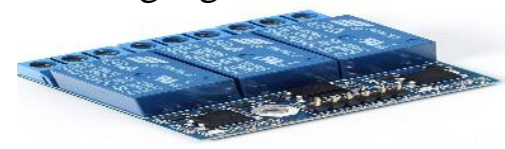

Gambar 2. Relay 3 Chanel

\section{Modul bluetooth}

Ada dua jenis bluetooth ke modul serial dengan ganjil dan genap. Bluetooth seri bernomor ganjil sebagai HC-05 atau HC-03 adalah versi perbaikan dari Bluetooth untuk Serial Modul HC-06 atau HC-04. Bluetooth ke serial modul HC-05 dapat ditetapkan sebagai master atau slave perangkat seperti HC-06 modul yang hanya bisa digunakan sebagai Slave [3]. Modul bluetooth yang digunakan menggunakan jenis HC-05, dimana tegangan kerja yang digunakan $5 \mathrm{~V}$, dan pin RX dan TX yang digunakan akan dihubungkan ke pin 10 dan 11 ke pin digital arduino.

\section{Pengenalan software controller Arduino.ide Arduino IDE (Integrated} Development Program) merupakan software yang dipakai untuk membuat sketch yang akan di upload ke board arduino sendiri. Arduino IDE juga tergolong bentuk software pengembangan program yang terintegrasi sehingga berbagai tools atau tampilan disediakan dan dinyatakan dalam bentuk antarmuka berbasis menu. Dengan menggunakan Arduino ide, kesalahan penulisan sketch atau kebenaran penulisan sketch langsung dapat dibuktikan [1]. Arduino. ide yang digunakan versi 1.0.6

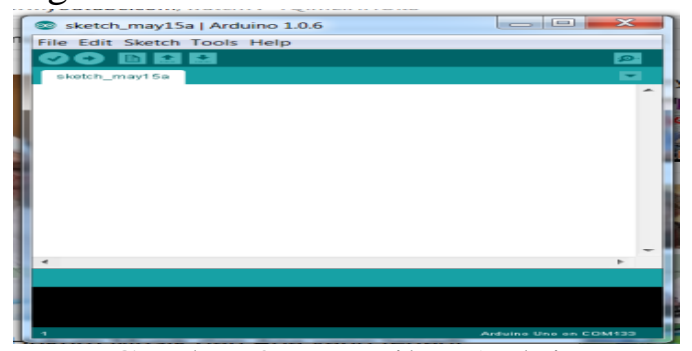

Gambar 3. Tampilan Arduino.IDE

\section{Mitt App Inventor}

App Inventor 2 (AI2) merupakan IDE generasi kedua dari App Inventor yang dikelola oleh Massachusetts Institute of Technology (MIT). AI2 berbasis cloud yang diakses menggunakan internet browser. Masuk kategori dalam visual programming, AI2 menggunakan block puzzle yang disusun untuk menjadi rangkaian kode [4].

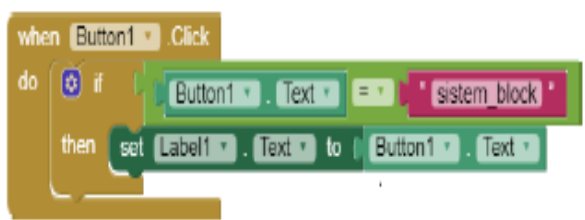

Gambar 4. Tampilan Block Program Inventor

\section{Perancangan hardware}

Rangkailah hardware arduino nano, relay dan modul bluetooth HC-05 sesuai dengan gambar 5. Tetapi arduino yang digunakan jenis Arduino Nano, dan untuk LED digantikan dengan relay.

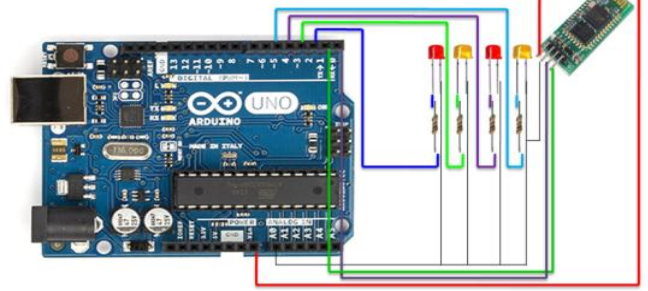

Gambar 5. Rangkaian Switch Lampu Menggunakan Android Dengan IOT 
Available online at https://jurnal.stmikroyal.ac.id/index.php/jurdimas

\section{Penjelasan penghubung pin pada} gambar 5 diatas, diantaranya :

1. Kaki Anoda LED 1 dihubungkan ke Kaki Restan 1 dan kaki restan yang tidak terhubung kemanapun, dihubungkan ke PIN 2 Arduino

2. Kaki Anoda LED 2 dihubungkan ke Kaki Restan 2 dan kaki restan yang tidak terhubung kemanapun, dihubungkan ke PIN 3 Arduino

3. Kaki Anoda LED 3 dihubungkan ke Kaki Restan 3 dan kaki restan yang tidak terhubung kemanapun, dihubungkan ke PIN 4 Arduino

4. Kaki Anoda LED 4 dihubungkan ke Kaki Restan 4 dan kaki restan yang tidak terhubung kemanapun, dihubungkan ke PIN 5 Arduino

5. Kaki Katoda LED 1-4 dihubungkan ke GND Arduino dan GND HC-05

6. PIN VCC HC-05 dihubungkan ke PIN 5V Arduino

7. PIN RXD HC-05 dihubungkan ke PIN TX (PIN 1) Arduino

8. PIN TXD HC-05 dihubungkan ke PIN RX (PIN 0) Arduino

Catatan :Seluruh kaki led digantikan dengan kaki in relay, dan rangkaian tidak menggunakan restan.

Setelah rangkaian hardware selesai dirangkai, masukan sketc atau coading untuk arduino.ide. Buka aplikasi arduino.ide seperti gambar 3, dan masukan sketch dibawah.

char val;

void $\operatorname{setup}()\{$

PINMode(2,OUTPUT);

PINMode(3,OUTPU

PINMode(4,OUTPUT);

Serial.begin(9600);

\}

void $\operatorname{loop}()\{$

if( Serial.available ()$>0$ ) \{

val $=$ Serial. $\operatorname{read}()$

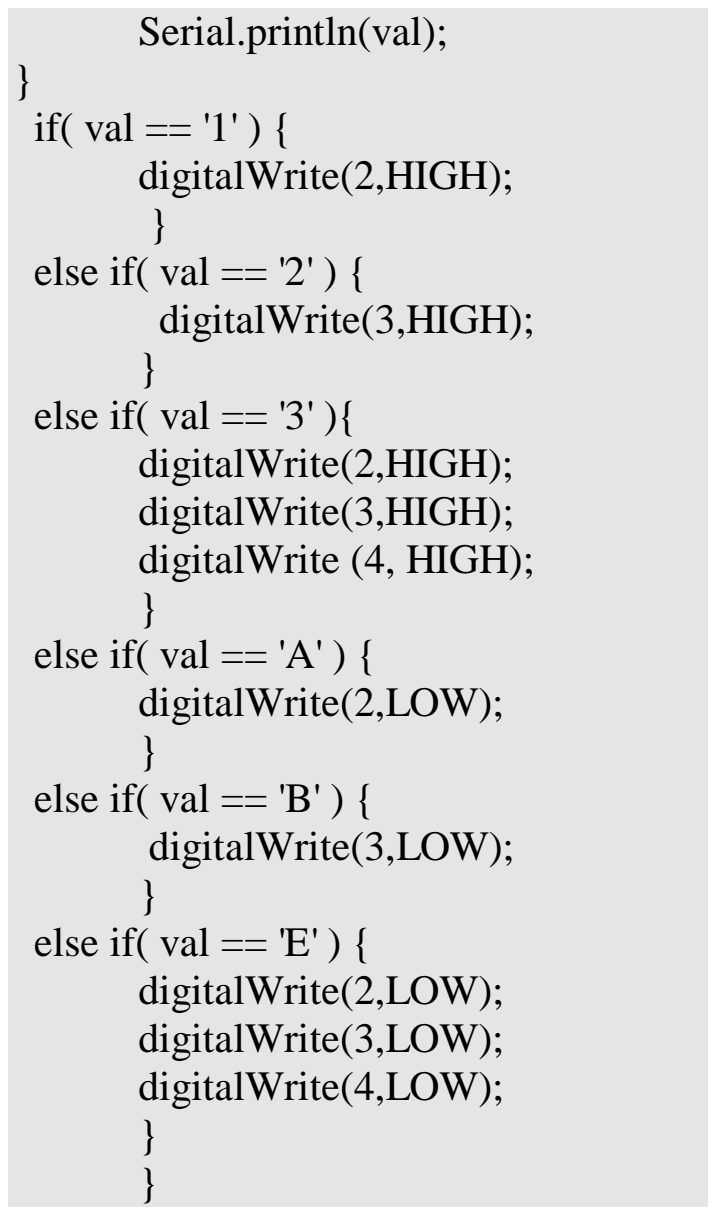

Setelah sampai ditahap ini maka penyelesaian project sudah berada ditahap $70 \%$, tinggal perancangan software untuk android.

\section{Perancangansoftware}

Adapun tahapan perancangan software android, di ai 2 inventor :

1. Masuk ke mozzilla/google chrome.

Selanjutnya masuk ke http://ai2.appinventor.mit.edu/

2. Akan tampil, tampilan awal App Inventor, seperti yang ditunjukan pada gambar 6 .

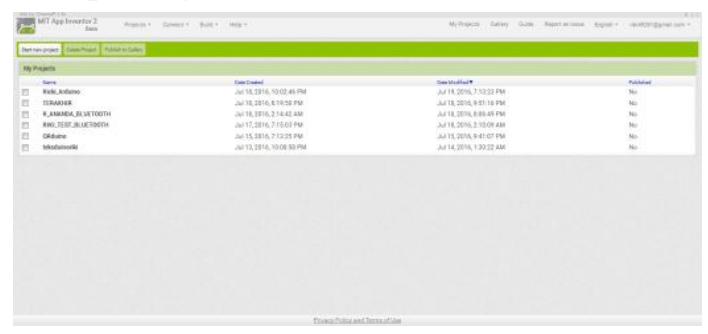

Gambar 6. Tampilan Awal Ai2 Inventor 
Available online at https://jurnal.stmikroyal.ac.id/index.php/jurdimas

3. Buat tampilan tombol seperti gambar 7 untuk listPicker dan label didapat di User Interface, sedangkan untuk clock terdapat di Sensor, sementara untuk Bluetooth Client didapat di Connectivity.

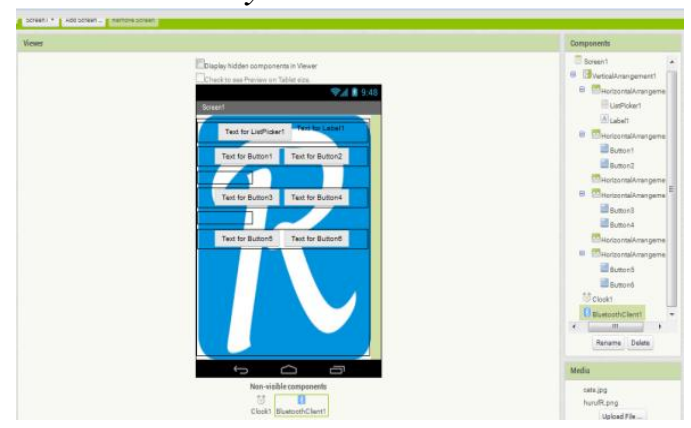

Gambar 7. Tampilan Tools Untuk Android

4. Masukan block bahasa program pada gambar 8 , yang bertujuan untuk menjalankan aplikasi android untuk arduino.

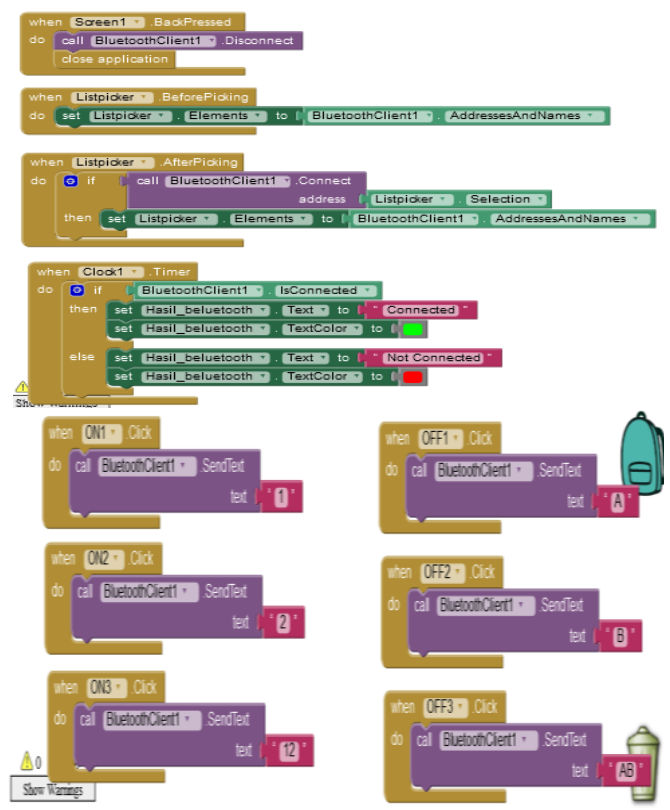

Gambar 8. Block Program Ai2 Inventor

5. Jika block bahasa program sudah di buat, langkah terakhir yang perlu kita lakukan adalah menyimpan aplikasi ke android atau mendownload nya, dengan cara klik Build maka akan tampil 2 pilihan, App (provide $Q R$ code for.apk) yang berfungsi untuk mendownload aplikasi melalui software tambahan di android MIT AI2 Companion, bisa didownload di playstore, dan yang satu lagi App (save. apk to my computer), di download melalui computer/laptop dan kemudian di install di android. Pada gambar 9. Tampilan aplikasi yang telah kita buat pada handphone.

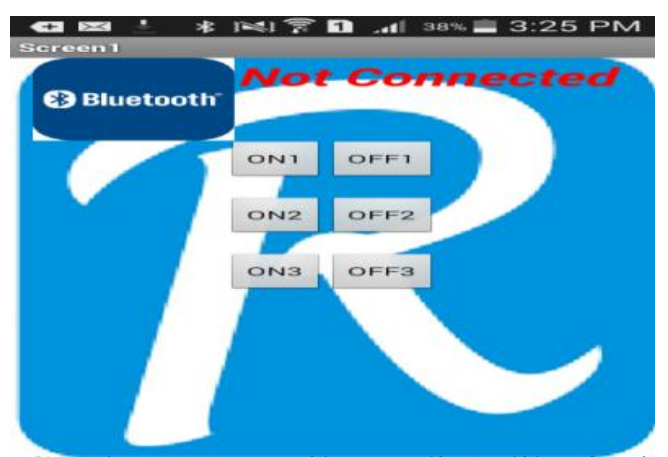

Gambar 9. Tampilan Jadi Aplikasi Di Android

Setelah sampai ditahap ini, maka project sudah siap untuk dioperasikan, tinggal menghubungkan android dengan modul bluetooth hc-05. Cara untuk menghubungkan antara modul bluetooth dengan hc-05, sama dengan cara menghubungkan kedua buah handphone pada saat proses pengiriman data.

Gambar dibawah, menunjukan dokumentasi pada saat merakit hardware switch relay berbasis iot.

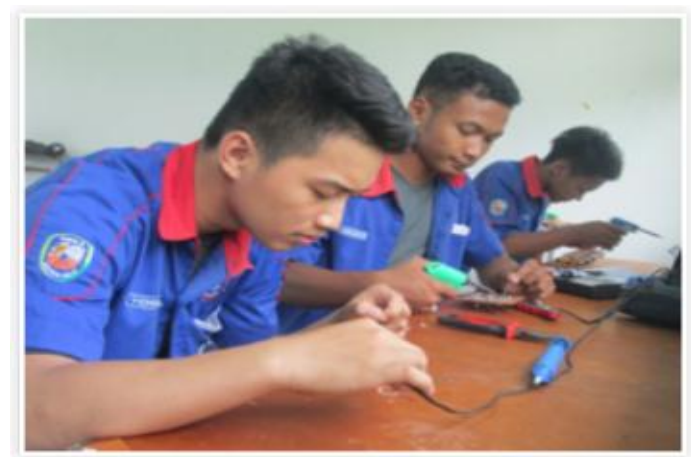

Gambar 11. Siswa Yang Sedang Membuat Rangkaian Switch Otomatis Berbasis Iot 


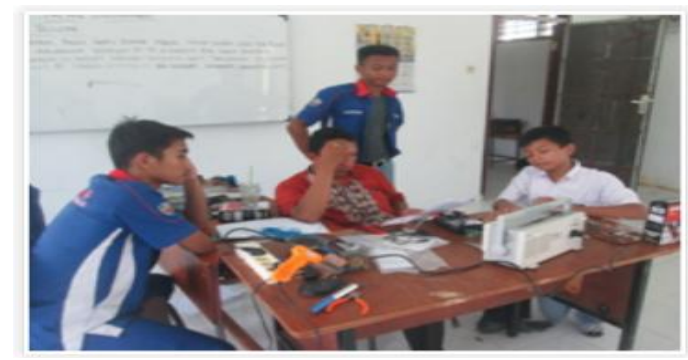

Gambar 12. Pemateri Bersama Siswa Menguji Coba Rangkaian Yang Sudah Selesai Dibuat

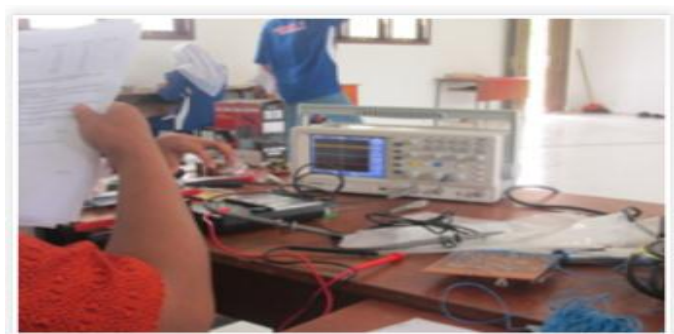

Gambar 13. Hasil Pengujian Rangkaian Dilihat Dari Serial Monitor Dan Oscilloscop

\section{SIMPULAN}

Berdasarkan uraian kegiatan yang pengabdian yang dilakukan di SMK Swasta Karya Utama, Kota tanjungbalai, maka didapat hasi, berupaka kesimpulan diantaranya:

1. Dari total jumlah 53 siswa yang mengikuti kegiatan pelatihan selama 2 hari, maka didapati bahwa hari pertama pelatihan, ada 7 siswa yang tidak menyelesaikan perancangan hardware, hal ini dikarenakan, ke 7 orang siswa tersebut masih bingung dalam membaca rangkaian dan masih asing dengan sistem controller.

2. Pada hari kedua dilakukan kegiatan workshop, dengan topik pembuatan software rangkaian, seluruh peserta berhasil membuat software switch otomatis di android berbasis iot, dengan persentasi keberhasilan uji coba rangkaian $100 \%$. Hal ini dikarenakan seluruh siswa sudah tidak asing dalam pembuatan software, baik software di computer, maupun software untuk android.

\section{DAFTAR PUSTAKA}

Akhmad dan kawan kawan.2015. Implementasi bluetooth HC-05 untuk memperbarui informasi pada perangkat running text berbasis android. EECCIS. vol 9. no 2.

Endar dan dwi. 2017. Pengembangan aplikasi android menggunakan integrated development environment (IDE) App inventor 2. Vol 4. no 1. Jurnal ilmiah edutic. e.ISSN 2528-7303.

Muhammad dan munik. 2017.Rancang bangun sistem keamanan rumah menggunakan relay. Jurnal teknologi elektro. Universitas mercubuana. Vol 8. No 3. ISSN: 2086-9479.

Ricki Ananda. 2016.40 Project robotik dan aplikasi android. Deepublish. Yogyakarta. 